\title{
The Biohistorical Paradigm: The Early Days of Human Ecology at The Australian National University ${ }^{1}$
}

\author{
Stephen Boyden² \\ Emeritus Professor \\ Fenner School of Environment and Society \\ The Australian National University, Canberra
}

Human ecology at The Australian National University (ANU) goes back to 1965 when a small group came into existence that was initially known as the Biology and Human Affairs Group. It was concerned with the constant interplay between human society and the processes of life that underpin our existence. This interplay is of immense consequence for us all.

It was not long before the Biology and Human Affairs Group became known as the Human Ecology Group.

In 1971, the Human Ecology Group came up with the proposal to carry out a study of the ecology of the city of Hong Kong. This idea was canvassed around the university, and initially met with either stony silence or open ridicule. Just about everybody thought it was a crazy idea. Everybody, that is, except Frank Fenner, who was director of the John Curtin School of Medical Research at the time. He made crucial funding available that made it all possible. Later, further substantial financial support was provided by other sources, including the Nuffield Foundation and UNESCO (United Nations Educational, Scientific and Cultural Organization).

Eventually, the Hong Kong Human Ecology Program became a cooperative effort between the ANU group and CSIRO, ${ }^{3}$ the University of Hong Kong, the Chinese University of Hong Kong, and the Hong Kong Government. It was eventually adopted by UNESCO as the first project in the urban settlements section of the Man and the Biosphere Program.

\footnotetext{
1 The concepts discussed in this essay have been further developed in Dyball and Newell (2015) and Boyden (in press).

2 Author contact: sboyden@netspeed.com.au.

3 Commonwealth Scientific and Industrial Research Organisation, Australia's national science agency.
} 
The Hong Kong study involved describing:

1. important aspects of the metabolism of Hong Kong, with special emphasis on flows of energy, carbon, water, and phosphorus in the system

2. the environments and conditions of life of different sections of the human population (e.g., housing, commuting and working patterns, population density, noise levels, diet)

3. patterns of health and disease in the human population.

The findings were published in numerous scientific papers and in a book titled The Ecology of a City and Its People: The Case of Hong Kong (Boyden et al., 1981).

The Hong Kong project was followed by a study, on a smaller scale, of the human ecology of the city of Lae and its hinterland in Papua New Guinea. This project was directed by Ken Newcombe.

This was all taking place in the ANU Institute of Advanced Studies, which was not involved with undergraduate education. However, in 1972, the Human Ecology Group proposed that an undergraduate program be introduced at ANU which would offer a series of integrative transdisciplinary courses on the human condition. Human ecology was to be a major component of this program. There was an interesting and amazingly vehement opposition to this idea from some quarters in the university. The proposed courses were simply not recognized as subjects worthy of academic pursuit.

However, approval for the program was eventually forthcoming. It was known as the Human Sciences Program and it lasted some 25 years, due to the efforts of people like Val Brown, Ian Hughes, David Dumaresq, and Rob Dyball. After that time its courses were largely taken over by the Fenner School of Environment and Society.

Something needs to be said about our theoretical approach. When I say "our," I am referring to a band of some 25 to 30 enthusiastic individuals who made up the Human Ecology Group in the John Curtin School, and later in the Centre for Resource and Environmental Studies, over the 25 years from 1965- too many to mention by name.

We refer to our conceptual approach as "biohistory," which we define as the study of human situations against the background of the story of life on Earth. Biohistory is, of course, a big subject. Here I will confine my comments to five themes that have been of special interest to us. I will discuss them under the following headings: 
- Conceptual approach

- Cultural maladaptation and reform

- Watersheds in biological and cultural evolution

- Biometabolism and technometabolism

- Evolution and human health

- Hope for the future.

\section{Conceptual approach}

Biohistory takes, as its starting point, the history of life on Earth.

In the beginning there was no life. Only the physical world existed-called the "Physical environment" in Figure 1. Then, perhaps around 4.5 billion years ago, the first living organisms came into being.

Eventually, over many hundreds of millions of years there evolved an amazing array of different life forms. Among these, emerging some 200,000 years ago, was Homo sapiens. Because of this animal's special relevance to our studies, it is separated from other living organisms in our conceptual scheme ("Human species" in Figure 1).

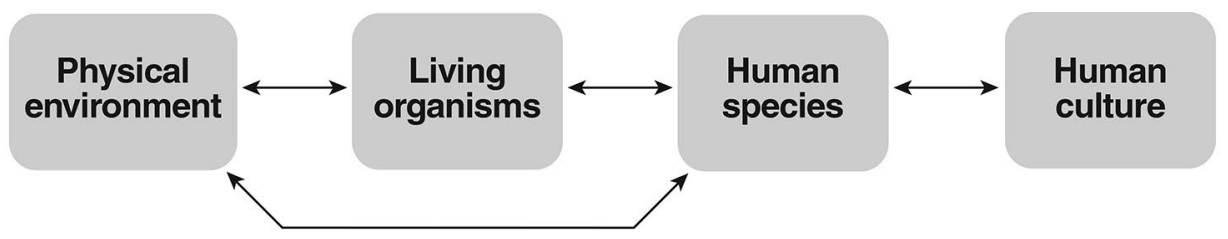

Figure 1. Conceptual starting point

Source: Stephen Boyden

Through the processes of biological evolution, humans had acquired a distinctive and extraordinarily significant biological attribute - the ability to invent and learn a symbolic spoken language, and to use it for communicating among themselves.

This aptitude for language led to the accumulation of shared knowledge, beliefs, and attitudes in human groups. That is, it led to human culture. ${ }^{4}$

Humans are also adept at inventing and applying new technologies, and knowledge of these technologies is a crucial component of culture.

4 The word culture is used here to mean the world view and accumulated knowledge, assumptions, beliefs, priorities, and values of a human population. It includes knowledge of language and technologies. 
As soon as human culture came into existence it began, through its influence on people's behavior, to have impacts not only on humans themselves but also on other living systems. It evolved as a new kind of force in the biosphere, destined eventually to bring about profound and far-reaching changes across the whole planet.

For the purposes of this discussion, it is useful to complicate the scheme a little. Because we are especially interested in the impacts on humankind and on the environment of what people actually do, it is useful to split humans into human population and human activities (Figure 2).

Human culture is also divided into two parts.

The first part is culture itself, which is the information stored in human brains and transmitted through language. The focus in our work has often been on the dominant culture of a society - that is, the culture that largely determines the patterns of human activity in that society.

The second part is designated societal arrangements, which includes society's economic, regulatory, political, and educational arrangements, and its institutional structure. Societal arrangements are largely determined by, and to some extent determine, the characteristics of the dominant culture.

In Figure 2 we have added another set of variables - namely artefacts, by which we mean "things made by humans," including buildings, roads, all kinds of machines and electronic devices, as well as clothes, utensils, and works of art.

Although this conceptual framework is based on the sequence of happenings in the history of life on Earth, it can also be applied to the here and now. The same sets of variables are involved. Located at the base of the model are the physical environment and living organisms - underpinning and supporting the human population, which in turn creates and maintains human culture.

We have found this conceptual framework useful for thinking and communicating about the human place in nature. 


\section{Humankind}

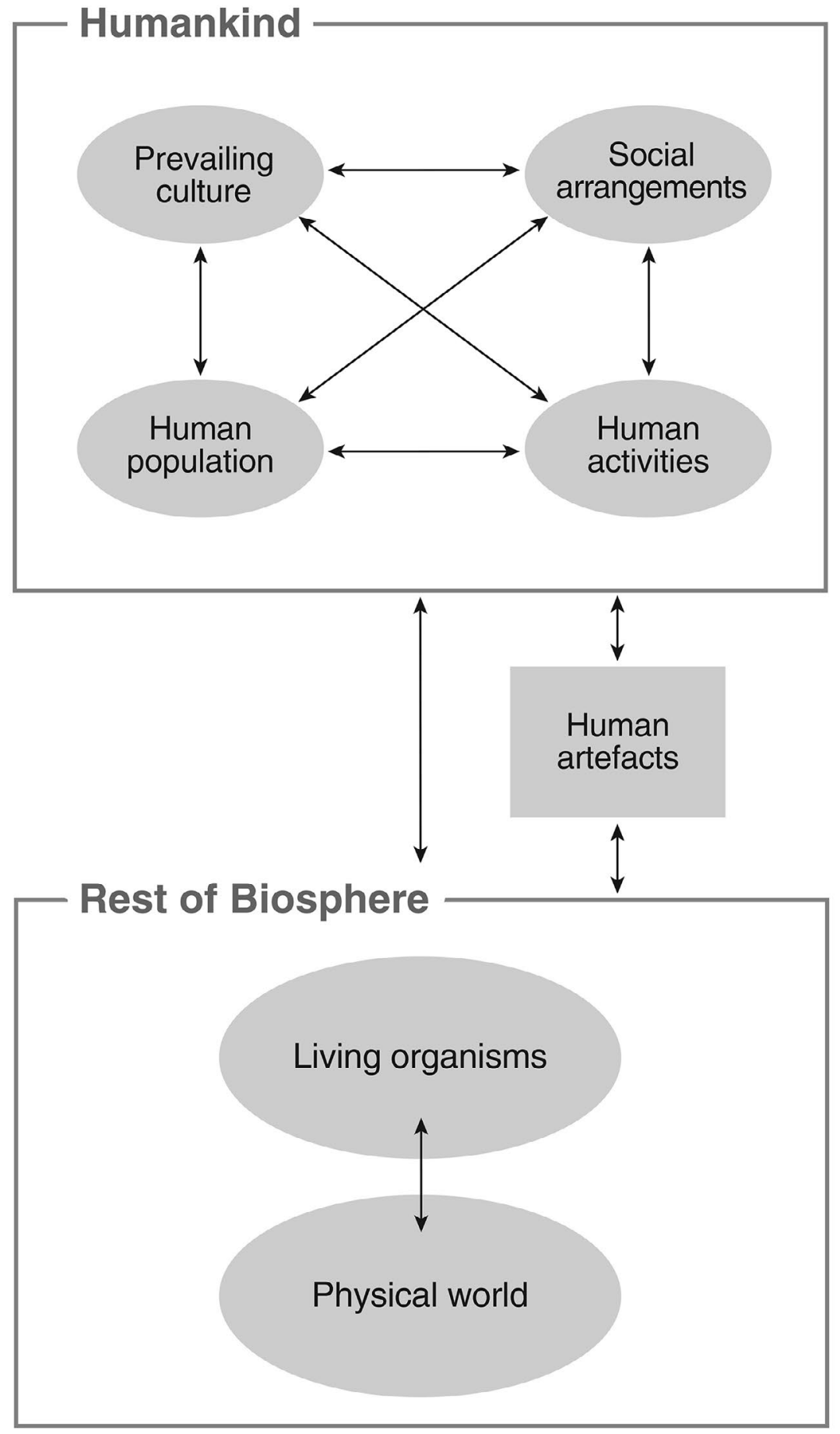

Figure 2. Conceptual framework Source: Stephen Boyden 
I would like to emphasize three points:

1. Including the cultural dimension in this framework is critically important. Cultural factors are of vital importance as powerful forces in the living systems of our planet today. It is unscientific to ignore them simply because they are difficult to quantify - or because culture is the domain of the humanities. To do so can only lead to an incomplete and therefore misleading picture.

2. The historical perspective is crucially important for understanding the human ecological situation today.

3. The study of the interplay between human culture and living systems brings to mind fundamental principles that are important for the understanding of human situations and problems in the modern world. Some of these principles will be discussed below.

\section{Cultural maladaptation and reform}

\section{Cultural maladaptation}

The rapidity of the evolutionary development of the capacity for culture indicates that, once a rudimentary ability to invent and use symbolic spoken language emerged, it was at once of major biological advantage under the prevailing conditions.

In my view, its chief advantage lay in its role in the exchange and storage of useful information about the environment. This information was not only communicated within the group, but was also passed on to members of subsequent generations, increasing the likelihood of their good health and successful reproduction. ${ }^{5}$

Apart from its practical advantages, culture adds richness to human experience. It did so in the days of our hunter-gatherer ancestors - as in storytelling, musical traditions, dancing, and other forms of artistic expression. And it does so today in so many ways. It makes a huge contribution to the sheer enjoyment of life.

However, especially under conditions of civilization, cultural evolution has often resulted in activities that have caused a great deal of unnecessary distress to humans or damage to ecosystems. Such undesirable culturally inspired activities are referred to as cultural maladaptations.

5 The fact that the capacity for culture was of biological advantage during the tens of thousands of generations of our species before the advent of agriculture does not mean, of course, that it will necessarily be an advantage under conditions quite different from those of the evolutionary habitat. 
A particularly tragic example of cultural maladaptation was the ancient Chinese custom of foot-binding, which prevented the normal growth of the feet of young girls and caused them excruciating pain. This extraordinary practice well illustrates the propensity of culture to influence people's mind-sets in ways that result in activities that are not only nonsensical in the extreme, but also sometimes very cruel and destructive and contrary to nature. This particular cultural maladaptation was mutely accepted by the mass of the Chinese population for 40 or more generations.

Throughout the history of civilization, different cultures, including our own, have come up with a fascinating range of delusions about how social wellbeing, or prosperity, can best be achieved, and some of these delusions have led to blatant examples of cultural maladaptation. Here I will mention only one instance.

According to the dominant culture of the Mayan civilization, prosperity could best be achieved by pleasing the gods, and the best way to please the gods was to torture, mutilate, and then sacrifice human beings. This behavior can be regarded as a cultural maladaptation because it caused a great deal of unnecessary human suffering.

Again, the point to be emphasized is the fact that while there may well have been a handful of skeptics among the Mayans, the great majority of them really believed that the torture and sacrifice of humans was an entirely appropriate behavior.

Cultural gullibility is indeed a fundamental characteristic of our species.

Biohistory thus alerts us to the need for us to be constantly vigilant - checking that the assumptions of our society's dominant culture are in tune with the processes of life - and that they are not leading us to behave in ways that are against nature or causing unnecessary human distress.

\section{Cultural reform}

Our species shares with all other animals a series of adaptive mechanisms, which include genetic adaptation through natural selection (adaptation of populations over many generations), many kinds of physiological adaptation, and adaptation through learning.

Humans, however, have an extra string to their bow-namely cultural adaptation, which is defined as adaptation through cultural processes. 
In the present context we are especially interested in cultural adaptation aimed at overcoming the undesirable consequences of culture itself - that is, adaptation to cultural maladaptations. We refer to this as cultural reform.

The processes of cultural reform are often quite complicated, involving prolonged interactions between different interest groups in society. A key role is often played initially by minority groups, occasionally by single individuals, who start the ball rolling by drawing attention to an unsatisfactory state of affairs. We can refer to these people as first-order reformers. A prime example of a first-order reformer is Rachel Carson who, in her ground-breaking book Silent Spring, drew attention to the insidious and destructive ecological impacts of certain synthetic pesticides (Carson, 1962).

Almost invariably, the expressions of concern coming from first-order reformers are promptly contradicted by others, the counter-reformers. This backlash often involves representatives of vested interests who fear that the proposed reforms will be to their disadvantage. They are likely to argue that the problem does not exist or that it has been grossly exaggerated, and they try to ridicule the reformers by calling them alarmists, fanatics, scaremongers, and prophets of doom. It is noteworthy that there is often a smattering of scientists among the counter-reformers (Oreskes \& Conway, 2010). Nowadays some of these counterreform forces are extraordinarily powerful.

The first-order reformers are, in time, joined by second-order reformers who also take up the cause. Eventually, if they are successful, a change comes about in the dominant culture and members of government bureaucracies and other organizations set about working out ways and means to achieve the necessary changes. Their efforts may still be hindered to some extent by the stalling tactics of counter-reformers.

A well-documented instance of cultural reform from the past is the Public Health Movement of the later part of the nineteenth century (Flinn, 1965; Frazer, 1950). Other more recent examples include the anti-smoking campaign and the current debates about climate change. In the latter case, the counter-reformers are often referred to as climate change deniers.

\section{Watersheds in biological and cultural evolution}

It is well recognized that biological evolution has been marked by a series of highly significant watersheds - after each of which a new situation emerged and nothing was ever the same again. 
Especially important among these watersheds were the development of photosynthesis, the appearance of cells with nuclei, the advent of multicellularity, and the invasion of land by life forms.

The most recent all-important watershed in biological evolution was the evolutionary emergence of the human capacity for language and culture. As discussed above, human culture eventually developed into a new and extremely powerful force in the biosphere, with far-reaching ecological consequences.

Cultural evolution, like biological evolution, has been marked by a series of watersheds, each of which ushered in a new ecological phase of human existence. ${ }^{6}$

The first of these cultural watersheds was the shared knowledge of how to make use of and, up to a point, control fire. The deliberate and regular use of fire was an important feature of Ecological Phase 1 of human history, the HunterGatherer Phase (Figure 3). This phase lasted for some 200,000 years. During this time Homo sapiens spread from Africa, and by 11,000 years ago, possibly much earlier, our species had reached all five habitable continents.

\begin{tabular}{|l|l|}
\hline $\begin{array}{l}\text { Cultural watershed and } \\
\text { approximate starting date }\end{array}$ & Followed by \\
\hline $\begin{array}{l}\text { Use and control of fire } \\
200,000 \text { years before present? }\end{array}$ & $\begin{array}{l}\text { Ecological Phase 1 } \\
\text { Hunter-Gatherer Phase }\end{array}$ \\
\hline $\begin{array}{l}\text { Farming } \\
12,000 \text { years before present }\end{array}$ & $\begin{array}{l}\text { Ecological Phase } 2 \\
\text { Early Farming Phase }\end{array}$ \\
\hline $\begin{array}{l}\text { Urbanization } \\
8,000 \text { years before present }\end{array}$ & $\begin{array}{l}\text { Ecological Phase 3 } \\
\text { Early Urban Phase }\end{array}$ \\
\hline $\begin{array}{l}\text { "Enlightenment" and } \\
\text { Industrial Revolution }\end{array}$ & $\begin{array}{l}\text { Ecological Phase 4 } \\
\text { Exponential Phase or Anthropocene } \\
\text { Unsustainable ecologically, leading to the collapse of civilization, } \\
\text { with great loss of life- unless humankind moves to Ecological } \\
\text { Phase 5. }\end{array}$ \\
\hline Biorenaissance & $\begin{array}{l}\text { Ecological Phase } 5 \\
\text { Biosensitive Phase } \\
\text { Based on understanding the human place in nature. In tune } \\
\text { with, sensitive to, and respectful of the processes of life. }\end{array}$ \\
\hline
\end{tabular}

Figure 3. Watersheds in cultural evolution

Source: Stephen Boyden

6 The emphasis here is in ecologically significant watersheds. There were also cultural watersheds affecting other aspects of human society. For example, in the sphere of the communication and storage of information, the introduction of writing and recently of information technology were hugely significant watersheds. 
The second crucial watershed was the advent of farming. It led to Ecological Phase 2, the Early Farming Phase, which began around 480 generations ago. This was indeed a turning point in cultural evolution. Without it, the spectacular developments in human history since that time would not have been possible.

The third crucial watershed in cultural evolution was the advent of urbanization - beginning around 300 generations ago, but really getting under way about 250 generations ago when fully fledged cities with populations of tens of thousands were in existence in Mesopotamia. And there were cities with populations of a few thousand in Peru at this time. This was the beginning of Ecological Phase 3- the Early Urban Phase. For the first time in human history, very large numbers of people were separated from the natural environment and played no role in the acquisition of food, and urban cultures evolved that regarded the natural world as alien and threatening.

The ecology of these urban dwellers was very different from that of huntergatherers or early farmers.

The fourth cultural watershed consisted of the philosophical movement referred to, misguidedly, as the Enlightenment, and the subsequent Industrial Revolution. We say misguidedly because a more appropriate term would be Partial Enlightenment. Its great weakness lay in its association with the idea that nature is out there to be conquered.

This fourth cultural watershed led to Ecological Phase 4, the Exponential Phase. This phase has also been dubbed 'the Anthropocene' (Crutzen \& Stoermer, 2000).

Ecological Phase 4 has been characterized by huge changes in the ecological relationships between human populations and the rest of the living world. There are now about 1,500 times as many people alive as there were when farming began. Seventy-five percent of this increase has occurred over the past 80 years.

Not only are there 1,500 times as many humans in existence, but these people are using vastly more resources and energy per capita. The human species as a whole is now using about 20,000 times as much energy per day as was the case when farming began. This is equivalent to the difference in weight between a small apple and a couple of tonnes of bricks. And well over $90 \%$ of this increase has occurred over the past 80 years.

The human population is now responsible for the emission of about 10,000 times as much carbon dioxide every day as was the case when farming began (Figure 4). Again, 90\% of this increase has occurred over the past 80 years. 


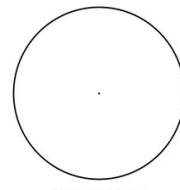

$10,000 \mathrm{BP}$

One dot $=3.5 \times 10^{6}$ tonnes of carbon dioxide pery

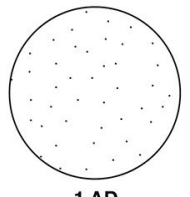

$1 \mathrm{AD}$

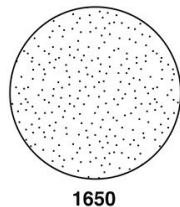

1650
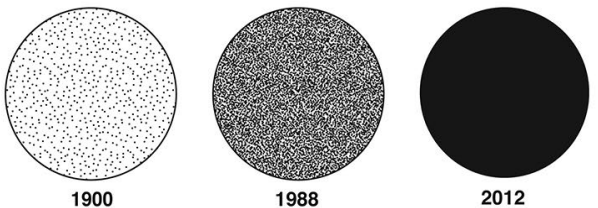

Figure 4. Carbon dioxide production by the human species

Source: Calculations by the author.

We don't have to be ecologists to appreciate that the living systems of our planet that support humankind will not be able to tolerate this onslaught forever. At present, anthropogenic climate change is the most critical result of cultural maladaptation. It may well be that the average temperature across the planet will be 4 degrees Celsius above the preindustrial level by the end of this century, with devastating consequences for humanity. But there are many other serious ecological threats to sustainability (Box 1).

\section{Box 1. Some recent consequences of cultural maladaptation}

- A steady and continuing increase in the atmospheric concentration of the greenhouse gas carbon dioxide, from the pre-industrial level of 280 parts per million by volume to 392 parts per million in 2011. There is strong evidence that this change is leading to increases in temperatures across the globe and other climatic changes.

- Destruction of $80 \%$ of the world's original forests. At present trees are felled in the Amazonian forests at the rate of 2,000 a minute.

- Severe land degradation (e.g., loss of organic matter, soil erosion, salinization).

- Worldwide loss of biodiversity - on land and in the oceans.

- Major interference with the natural nutrient cycles on which life depends.

- Persistent organic pollutants, which are synthetic compounds used as pesticides and for other purposes, now found in the tissues of humans and other animals all over the world, including oceanic species. They can cause ill health or death and they interfere with reproductive processes.

- Acidification of the oceans resulting from the uptake of anthropogenic carbon dioxide from the atmosphere.

- Thousands of weapons of mass destruction stored in the arsenals of the worldmany times more than necessary to bring an end to the human species.

- Extreme disparities in health and material wealth among human populations (not the case for the first 190,000 years of our species).

Humans are overstepping the mark in a big way. If present trends continue unabated the collapse of civilization is inevitable. The days of Ecological Phase 4 are numbered. 
The most disturbing feature of the present situation is the fact that the dominant cultures of the world today are blissfully unaware of these ecological realities. They have lost sight of our total dependence on the processes of life in and around us, and they have no grasp of the nature, magnitude, and seriousness of current human impacts on the ecosystems of our planet. The world views, assumptions, and priorities of these cultures are totally incompatible with the achievement of ecological sustainability, and hence the survival of civilization.

\section{Biometabolism and technometabolism}

An important theme in biohistory is the changing patterns of metabolism of human populations.

Every population of living organisms takes up nutrients and energy from its environment, makes use of them in the processes of life and then discharges wastes and gives off the energy in the form of heat.

In the case of the human species, cultural evolution has led to an extra dimension to population metabolism. In addition to a population's biometabolism, which consists of the inputs, throughputs, and outputs of energy and materials involved in physiological processes within human bodies, there is also a significant technometabolism. This consists of the inputs, uses, and outputs of energy and materials involved in technological processes taking place outside human bodies. Technometabolism is a new phenomenon in the history of life on Earth and is of tremendous ecological significance.

Already in the Hunter-Gatherer Phase of human existence, technometabolism became important through the regular use of fire. This resulted in significant changes in the life conditions of humans by providing them with warmth and leading to the consumption of cooked foods. In some regions, the use of fire by hunter-gatherers sometimes resulted in important ecological changes in the local environment, leading to the replacement of large areas of woodland with grassland and resulting in big increases in the size of herds of grazing animals, and consequently in the supply of animal protein for humans. Fires resulting from human activities had a major impact on vegetation in parts of Australia long before the European invasion of the continent (Jones, 1969).

In Ecological Phase 4, industrialization has led to a massive increase in the intensity of the technometabolism of human populations. The most evident manifestation of this at present is anthropogenic climate change- but there are many others. 


\section{Technometabolic inputs}

Energy use is an important measure for a number of reasons. First, the rate of use of energy is probably the best single indicator of the overall intensity of human activity on the planet, since everything that we do involves, or requires, a throughput of energy. However, its impact depends a great deal, of course, on the particular use to which the energy is put. It also depends on the source of the energy, since some energy sources have by-products that have biological impacts of various kinds. These impacts include carbon dioxide, oxides of sulfur and nitrogen from fossil fuels, and radioactive by-products from nuclear power plants.

The main sources of extrasomatic energy throughout the industrial phase of society have been fossil fuels, although the relative contributions of coal, oil, and natural gas have changed over the past 60 years. In some countries, nuclear power has made a significant contribution to the generation of electricity.

Hydroelectricity, unlike fossil fuels and nuclear power, does not produce undesirable by-products, and it makes a significant contribution in regions where topography allows it. Use of other clean, non-polluting energy sources, such as wind and solar power, is also on the increase; but at present they contribute only a small fraction of the total energy budget.

Other technometabolic inputs into human societies today include a vast range of materials used in construction of buildings and roads and for the manufacture of machines and utensils as well as electronic devices. To take just one example, the per capita consumption of iron in Australia today, excluding the iron in manufactured goods imported from overseas, is around 1.3 kilograms per day. In Shakespeare's time it was probably about 1 gram per day.

\section{Technometabolic outputs}

Human activities in Ecological Phase 4 have resulted in the production of massive quantities of by-products of industrial processes, many of which have very serious ecological and health consequences. They include the chlorofluorocarbons (CFCs) that result in damage to the ozone layer, and the persistent organic pollutants that have spread into ecosystems right across the globe and that can cause serious ill health in many animal species, including humans.

At present the most critical output is carbon dioxide, which comes from the use of fossil fuels and as a result of deforestation. 
In 1965, Abel Wolman introduced the concept of urban metabolism and described the metabolism of a hypothetical city of one million inhabitants (Wolman, 1965). In 1975 and 1976, the Human Ecology Group at ANU and colleagues from CSIRO carried out an analysis of aspects of both biometabolism and technometabolism of Hong Kong, focusing on energy, carbon dioxide, water, and phosphorus (Newcombe et al., 1978).

In the final report of this work on Hong Kong, attention was drawn to the longterm unsustainability of the ever-increasing intensity of resource and energy use and waste production in this city (Boyden et al., 1981). This conclusion is shared by the authors of a more recent study of the metabolism of Hong Kong (Warren-Rhodes \& Koenig, 2001).

Since the 1970s there has been much work on urban metabolism, all of it indicating progressive increase in the intensity of resource and energy use and waste production (Kennedy et al., 2007).

\section{Evolution and human health}

Biohistory reminds us that our species has been in existence for some 8,000 generations and that we are basically the same animal as our ancestors who lived long before the advent of farming - that is, an animal genetically adapted through natural selection to the life of the hunter-gatherer. ${ }^{7}$ This fact has important implications for understanding ourselves and our problems.

One of the outcomes of the processes of evolution is the fact that animals become well adapted in their biological characteristics to the habitat in which they are evolving. In other words, the genetically determined characteristics of any species are such that the individual animals are likely to experience good health in their natural environment.

If an animal is removed from its natural environment, or if its environment changes significantly, then it is likely to be less well adapted to the new conditions, and consequently some signs of physiological or behavioral maladjustment can be expected. This evolutionary health principle is a fundamental law of nature (Boyden, 1973, 1987, 2004).

\footnotetext{
7 This does not mean that evolutionary change in the human species has come to a halt. There has been a relaxation of some selection pressures that were powerful in the hunter-gatherer environment and in the long term this will result in genetic changes in human populations (Rendel, 1970). There have also been some new selection pressures associated with the advent of farming that have produced changes in some populations. A well-known example of this is the emergence and spread in European populations of lactase production into adulthood in response to the availability of bovine milk as a food source. For discussion of this change and for other examples, see Cochran and Harpending (2009).
} 
Changes in conditions of life from the natural situation that are likely to cause maladjustment have been called evodeviations. Recent evodeviations in human populations include the consumption of refined carbohydrates and the practice of cigarette smoking.

It follows from the evolutionary health principle that if we wish to identify the health needs of any particular kind of animal, the first thing to do is to examine the conditions under which it evolved, because we can be sure that these conditions are capable of providing all the essential ingredients for maintaining and promoting health in that species.

In the case of our own species, for example, there is no diet better for us than the typical diet of our hunter-gatherer ancestors; if we take much more or much less physical exercise than a typical hunter-gatherer, or if we inhale chemical fumes that were not present in the evolutionary environment, then we are likely to experience signs of maladjustment.

There are good reasons for believing that the evolutionary health principle applies not only to such physical health needs as clean air and the need for physical exercise, but also to psychosocial aspects of life conditions. For example, the lives of hunter-gatherers are usually characterized by the experience of conviviality, effective emotional support networks, incentives and opportunities for creative behavior, and a sense of personal involvement in daily activities. Most of us would agree that such conditions are likely to promote health and well-being in our own society. It is important that we take them into account in assessing the quality of life today and in considering options for the future.

Taking our knowledge of the conditions of life of hunter-gatherers as a starting point, we can put together a working list of physical and psychosocial conditions likely to promote health and well-being in our species (Box 2). They are referred to as universal health needs because they apply to all members of the human species wherever or whenever they may be living. 


\section{Box 2. Universal human health needs}

\section{Physical needs}

- Clean air (not contaminated with hydrocarbons, sulfur oxides, etc.).

- A natural diet, that is, foods containing the full range of nutritional requirements, as provided by a diverse range of different plant foods and a small amount of cooked lean meat and offal; foods devoid of noxious contaminants or additives.

- Clean water (free of contamination with chemicals or pathogenic organisms).

- Electromagnetic radiation within the natural range.

- Minimal contact with parasites and pathogenic organisms.

- Natural contact with non-pathogenic microorganisms in the environment.

- Adequate protection from extremes of climate.

- Noise levels within the natural range.

- A pattern of physical exercise that involves some short periods of vigorous muscular work and longer periods of medium and varied muscular work, but also frequent periods of rest.

\section{Psychosocial needs}

- An emotional support network, providing a framework for care-giving and care-receiving behavior.

- The experience of conviviality.

- Levels of sensory stimulation neither much lower nor much higher than those of the natural habitat.

- Variety in daily experience.

- Opportunities and incentives for creative behavior and practicing manual skills.

- Opportunities and incentives for active involvement in recreational activities (e.g., dancing, making music).

- An environment and lifestyle conducive to a sense of belonging, challenge, selffulfillment, comradeship, love, purpose, and personal involvement in daily activities.

- An environment and lifestyle that do not promote a sense of alienation, anomie, deprivation, boredom, loneliness, or chronic frustration.

Most of the items on the list of postulated psychosocial health needs, like creative behavior and sense of personal involvement, cannot be defined and measured as easily as the physical health needs; but this does not mean they are less important.

The evolutionary health principle is of enormous relevance to the health professions, public health policies, and personal lifestyle choices. However, it is seldom mentioned in the medical literature. ${ }^{8}$

8 An exception is Cleave and Campbell (1966), who drew attention to the fact that diets containing refined carbohydrates deviated from the natural diet of the human species and consequently gave rise to various forms of maladjustment. 
Cultural evolution has led to numerous instances of cultural maladaptation resulting in ill health in human populations throughout the history of civilization. Many forms of ill health in our society today are the result of evodeviations including most cases of lung cancer, coronary heart disease, obesity, and probably much mental depression.

In this context, something must be said about the concept of stressors and meliors. The term "stressor" is commonly used for an experience that causes anxiety and distress. When stressors are excessive and persistent they can interfere seriously with both mental and physical health. During our work on the ecology of Hong Kong, we became aware of the immense importance of experiences that have the opposite effect to stressors, and which are associated with a sense of enjoyment. We decided to call such experiences "meliors."

The well-being of individuals at any particular time can be seen to be largely a function of their position on a hypothetical continuum between a state of distress at one extreme and a sense of well-being at the other. While stressors tend to push the individual toward a state of distress, meliors push in the opposite direction. A person's position on the continuum is thus the outcome of the balance between stressors and meliors. Social changes that result in the erosion of meliors are just as undesirable as those that result in an increase in stressors.

There is nothing particularly original about the melior-stressor concept. It is no more than everyday common sense. However, in academic discussion and research much more emphasis has been placed on stressors than on the opposite kinds of experience. Giving them the name meliors serves to remind us to take them properly into account in assessing existing conditions or options for the future.

One of the features of Ecological Phase 4 society today is the fact that the achievement of meliors is frequently much more costly, in terms of energy and resources, than it was in the past. The pursuit of meliors makes a substantial contribution to a society's technometabolism.

\section{Hope for the future: A fifth watershed in cultural evolution}

Cultural maladaptations in Ecological Phase 4 are manifold and some of them are on a scale unprecedented in the history of our species. The ecological unsustainability of the current patterns of human activity is now well appreciated. Our hope for the survival of civilization and the future well-being 
of humankind lies in the possibility that processes of cultural reform might lead us to an ecologically sustainable and healthy Phase 5 of human existence. It will be a phase in which our society is truly in tune with, sensitive to, and respectful of the processes of life that underpin our existence. We call this a biosensitive society. A biosensitive society will promote health and well-being in all sections of the human population and in the ecosystems of the biosphere (Figure 5).

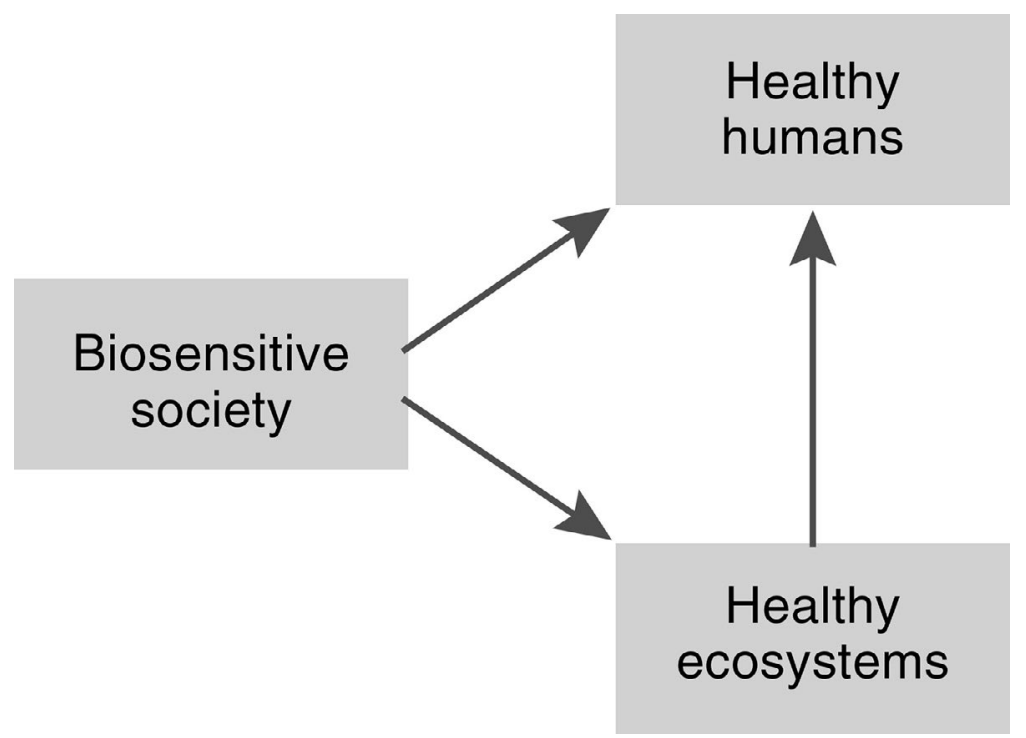

Figure 5. A biosensitive society

Source: Stephen Boyden

The transition to a biosensitive society will involve sweeping changes in the intensity and nature of human activities. It will require a major scaling down of resource and energy use and the eradication of all practices and technologies that interfere with or threaten human or ecosystem health. It will require revolutionary changes in societal arrangements, including the economic system and the occupational structure of society.

Biosensitivity will be the guiding principle in all spheres of human activityindividual and collective. This will mean biosensitive governments, biosensitive technologies, biosensitive transport systems, biosensitive industries, biosensitive farms, biosensitive forests, biosensitive cities, biosensitive buildings, and biosensitive lifestyles - and a biosensitive economy.

But there can be no shift to a biosensitive Phase 5 society until there comes about a radical transformation in the world views and priorities of the dominant cultures of the world. It will need a fifth watershed in cultural evolution (Figure 3), based on a shared understanding of the story of life on Earth and the human place in nature. We call this biounderstanding. 
Cultures that embrace biounderstanding will share a profound respect for the processes of life and will place the achievement of biosensitivity at the top of the social agenda - reflecting the reality that keeping the processes of life healthy is what matters most, because everything else depends on them.

We can call this cultural transformation a "cultural renaissance" - or perhaps "biorenaissance" - because many hunter-gatherer and early farming cultures in the past were characterized by a profound respect for the living world and an understanding that humans are part of nature and completely dependent on other life forms for their well-being and survival.

Of course, the social reform movement is well under way. There are countless individuals, community organizations, and nongovernmental organizations (NGOs) putting a great deal of effort into activities aimed at the achievement of ecological sustainability. But so far they represent only a small section of the community and their overall effect has been minimal. The juggernaut rolls on.

The most critical need right now is therefore for an international campaign to spread this biounderstanding globally. United Nations agencies have the means and the obligation to play a key role in this movement. In the meantime, individuals, community groups, and NGOs can start the ball rolling by promoting this kind of understanding right across the community, especially among those in positions of power and influence.

Professional human ecologists also have a pivotal role to play in bringing about the fifth watershed in cultural evolution. Their task is to spread this understanding across the disciplines within the academic world and to the community at large.

The survival of civilization - and perhaps of the human species - will depend on whether this fifth watershed in cultural evolution takes place.

\section{Books published by members of the Human Ecology Group}

Boyden, S. (Ed.). (1970). The impact of civilisation on the biology of man. Canberra: Australian National University Press.

Boyden, S. (1979). An integrative ecological approach to the study of human settlements (MAB Technical Notes No. 12). Paris: UNESCO.

Boyden, S. (1987). Western civilization in biological perspective: Patterns in biohistory. Oxford: Oxford University Press. 
Boyden, S. (1992). Biohistory: The interplay between human society and the biosphere - past and present. Paris: Parthenon/UNESCO.

Boyden, S. (2004). The biology of civilisation: Understanding human culture as a force in nature. Sydney: UNSW Press.

Boyden, S. (2005). People and nature: The big picture. Canberra: Nature and Society Forum.

Boyden, S. (2011). Our place in nature: Past, present and future. Canberra: Nature and Society Forum.

Boyden, S. (in press). The Bionarrative: The story of life and hope for the future. Canberra: ANU Press.

Boyden, S., Dovers, S., \& Shirlow, M. (1990). Our biosphere under threat: Ecological realities and Australia's opportunities. Melbourne: Oxford University Press.

Boyden, S., Millar, S., Newcombe, K., \& O'Neill, B. (1981). The ecology of a city and its people: The case of Hong Kong. Canberra: Australian National University Press.

Christie, M. (1980). Changing consumer behavior in Papua New Guinea: Its social and ecological implications. Canberra: Australian National University, Centre for Resource and Environmental Studies for UNESCO.

Dalton, K.J. (1979). Chimbu people under pressure: The social impact of urbanisation in Papua New Guinea. Canberra: Australian National University, Centre for Resource and Environmental Studies for UNESCO.

Jeffries, D.J. (1979). From Kaukau to Coke: A study of rural and urban food habits in Papua New Guinea. Canberra: Australian National University, Centre for Resource and Environmental Studies for UNESCO.

Millar, S. (1979). The biosocial survey in Hong Kong. Paris: UNESCO/UNEP.

Newcombe, K. (1980). Energy for development: The energy policy papers for the Lae project. Canberra: Australian National University, Centre for Resource and Environmental Studies for UNESCO.

\section{References}

Boyden, S. (1973). Evolution and health. The Ecologist, 3, 304-305.

Boyden, S. (1987). Western civilization in biological perspective: Patterns in biohistory. Oxford: Oxford University Press. 
Boyden, S. (2004). The biology of civilisation: Understanding human culture as a force in nature. Sydney: UNSW Press.

Boyden, S. (in press). The Bionarrative: The story of life and hope for the future. Canberra: ANU Press.

Boyden, S., Millar, S., Newcombe, K., \& O'Neill, B. (1981). The ecology of a city and its people: The case of Hong Kong. Canberra: Australian National University Press.

Carson, R. (1962). Silent spring. Cambridge, MA: Houghton Mifflin.

Cleave, T. L., \& Campbell, G. D. (1966). Diabetes, coronary thrombosis and the saccharine disease. Bristol: John Wright.

Cochran, G., \& Harpending, H. (2009). The 10,000 year explosion: How civilisation accelerated human evolution. New York: Basic Books.

Crutzen, P. J., \& Stoermer, E. F. (2000). The Anthropocene. Global Change Newsletter, 41, 17-18.

Dyball, R., \& Newell, B. (2015). Understanding human ecology: A systems approach to sustainability. London: Routledge.

Flinn, M. W. (Ed.). (1965). Report on the sanitary conditions of the labouring population of Britain (by E. Chadwick, 1842). Edinburgh: Edinburgh University Press.

Frazer, W. M. (1950). A history of English public health. London: Balliere, Tindall and Cox.

Jones, R. (1969). Fire-stick farming. Australian Natural History, 16, 224-231.

Kennedy, C., Cuddihy, J., \& Engel-Yan, J. (2007). The changing metabolism of cities. Journal of Industrial Ecology, 11, 43-59.

Newcombe, K., Kalma, J. D., \& Aston, A. R. (1978). The metabolism of a city: The case of Hong Kong. Ambio, 7, 3-13.

Oreskes, N., \& Conway, E. M. (2010). Merchants of doubt: How a handful of scientists obscured the truth on issues from tobacco smoke to global warming. London: Bloomsbury Press.

Rendel, J. M. (1970). The time scale of genetic change. In S. V. Boyden (ed.), The impact of civilization on the biology of man (pp. 27-47). Canberra: Australian National University Press. 
Human Ecology Review, Volume 22, Number 2, 2016

Warren-Rhodes, K., \& Koenig, A. (2001). Escalating trends in the urban metabolism of Hong Kong: 1971-1997. Ambio, 30, 429-438.

Wolman, A. (1965). The metabolism of cities. Scientific American, 213, 179-190. 
This text is taken from Human Ecology Review, Volume 22, Number 2, 2016, published 2016 by ANU Press, The Australian National University, Canberra, Australia. 